УДК 332.1 JEL R58

\section{Шемякина Татьяна Юрьевна}

канд. экон. наук, ФГБОУ ВО «Государственный университет управления», г. Москва, Российская Федерация

e-mail:Sh.tatiana@list.ru

\section{Shemyakina Tatiana}

Candidate of Economic Sciences, State University of Management, Moscow, Russia e-mail:Sh.tatiana@list.ru
DOI 10.26425/1816-4277-2019-6-82-89

\section{САМОРЕГУЛИРОВАНИЕ КАК ФАКТОР УСТОЙЧИВОГО РАЗВИТИЯ СТРОИТЕЛЬНЫХ ОРГАНИЗАЦИЙ}

\begin{abstract}
Аннотация. Проведен анализ законодательной базы перехода на саморегулирование в строительстве. Рассмотрены отличия и преимущества допуска к работам от строительной лицензии, проблемы контроля выполнения строительных работ на объектах, области применения государственного надзора. Исследована процедура участия саморегулируемой организации в выявлении и реагировании на нарушения, допущенные строительной организаиией. Рассмотрены функиии строительного контроля и их отличие от технического надзора. Предложены критерии отбора эффективных саморегулируемых организаций, введения предупредительного контроля, объединения функиий строительного контроля и надзора заказчика и саморегулируемой организации.
\end{abstract}

Ключевые слова: строительная лицензия, саморегулирование в строительстве, допуск, качество экспертизы, модель саморегулирования, критерии отбора саморегулируемых организаций, строительный контроль, технический надзор.

Цитирование: Шемякина Т.Ю. Саморегулирование как фактор устойчивого развития строительных организаций//Вестник университета. 2019. № 6. С. 82-89.

\section{SELF-REGULATION AS A FACTOR OF CONSTRUCTED ORAGNIZATIONS`SUSTAINABLE DEVELOPMENT}

\begin{abstract}
The legislative base of transition to self-regulation in construction has been analyzed. Differences and advantages of admission to works from the construction license, problems of control of construction works on objects performance, scopes of the state supervision have been considered. The procedure of SRO participation in identification and response to the violations, allowed by the construction organization, has been investigated. Functions of construction control and their difference from technical supervision have been considered. The criterion for the selection of effective self-regulatory organizations, the introduction of preventive control, combining the functions of construction control and supervision of the customer and self-regulatory organization have been offered.
\end{abstract}

Keywords: construction license, self-regulation in construction, admission, quality of examination, self-regulation model, selection criterion of SRO, construction control, technical supervision.

For citation: Shemyakina T.Yu. Self-regulation as a factor of constructed oragnizations` sustainable development (2019) Vestnik universiteta, I. 6, pp. 82-89. doi: 10.26425/1816-4277-2019-6-82-89

В 2009 г. в Российской Федерации (далее - РФ) в строительстве было введено саморегулирование, которое призвано заменить функции государственного регулирования строительных работ и оказывать содействие выработке государственной политики в области строительства, определении потребностей в профессиональных кадрах строительных специальностей и развитии современных строительных профессий.

Принятые законы «О саморегулируемых организациях», «О внесении изменений в Градостроительный кодекс» установили отмену лицензирования и переход к саморегулированию в строительном бизнесе, и с 2010 г. все выданные ранее строительные лицензии стали недействительными [1; 2].

Строительная лицензия - это документ на осуществление проектирования, архитектурно-строительных изысканий и всех видов строительных работ, которая выдавалась строительной организации

(C) Шемякина Т.Ю., 2019. Статья доступна по лицензии Creative Commons «Attribution» («Атрибуция») 4.0. всемирная (http://creativecommons.org/licenses/by/4.0/).

The Author(s), 2019. This is an open access article under the CC BY 4.0 license (http://creativecommons.org/licenses/by/4.0/).

(c) (i) 
или индивидуальному предпринимателю, выполняющему строительные работы. При этом обязательным условием было соблюдение требований лицензирующего органа.

Вместо строительной лицензии строительные организации, чья деятельность связана со строительством, проектированием и изысканиями, получают свидетельство о допуске к работам, которое выдается саморегулируемой организацией (далее - СРО). Допуск отличается от строительной лицензии тем, что он:

- выдается на работы на всей территории РФ;

- означает профессионализм компании и дает гарантию высокого качества работ;

- действует бессрочно;

- выдается в сжатые сроки.

Строительная организация получает допуск на выполнение работ только при условии ее членства в СРО. При этом если организация работает в нескольких направлениях - в строительстве, проектировании и изысканиях - необходимо вступить в СРО по каждому их них.

Допуск СРО является документом, свидетельствующим о законности осуществления строительной деятельности. Отсутствие допуска влечет за собой наложение административного штрафа, а в некоторых случаях - уголовную ответственность и ликвидацию строительной организации [6].

После перехода полномочий по выдаче строительных лицензий саморегулируемым организациям на рынке строительных услуг сформировался новый механизм контроля и ответственности, позволяющий улучшить качество и безопасность строительных работ.

В соответствии с внесенными изменениями в Градостроительный кодекс РФ в 2016 г. и в 2018 г., были определены дополнительные задачи и зоны ответственности для СРО и их объединений, которым были предписаны функции взаимодействия с исполнительными и законодательными органами государственной власти. Была также введена система учета и ведения реестра специалистов на базе Ассоциации «Национального объединения строителей» (далее - НОСТРОЙ) и «Национального объединения изыскателей и проектировщиков» (далее - НОПРИЗ). Таким образом, зародилась система учета профессиональных кадров в сфере строительства в России [3].

С принятием данного закона система саморегулирования в строительстве стала решать задачи не только совместного принятия решений государством, бизнесом и общественными объединениями, но и надлежащего обеспечения профессиональными кадрами - рабочими, инженерами - и, в том числе, формировать общественный заказ на образование и «профессию» для системы высшего, среднего и профессионального технического образования. Это позволяет реализовывать требование качественного выполнения проектных и строительных работ организациями, получающими допуск СРО.

В связи с развитием саморегулирования в результате перехода на новые требования Градостроительного кодекса РФ потребовалось привести формат работы СРО в соответствие с новыми нормами законодательства. Этот процесс вызвал проблемы у многих СРО, которые не смогли своевременно и ответственно выполнить поставленные задачи, в частности сформировать компенсационные фонды и в полном объеме разместить средства компенсационных фондов СРО на специальных счетах в банках, привести в соответствие внутренние документы СРО, обеспечить выполнение договорных обязательств своих членов. Для снижения денежной нагрузки членов строительных СРО возможно также доходы, полученные от размещения на депозитах средств компенсационного фонда СРО, использовать в качестве доплаты взноса в компенсационный фонд для обеспечения договорных обязательств [5].

Законодатель определяет условия и принципы работы, СРО обеспечивает информированность своих членов об изменениях в законодательстве, контролирует исполнение договорных обязательств членов, оказывает помощь в разрешении возникающих в ходе исполнения договоров текущих проблем, и конечно, обеспечивает сохранность компенсационных фондов. С начала введения закона 2016 г. на специальный счет НОСТРОЙ было зачислено 2,5 млрд руб. Из них по поступившим заявлениям строителей НОСТРОЙ перечислил на специальные счета действующих СРО более 1,42 млрд. руб. [11].

На средства исключенных СРО, размещенные на специальном счете НОСТРОЙ, только в 2018 г. был начислен доход в размере свыше 50 млн руб. В 2017-2018 гг. в адрес НОСТРОЙ поступило 7770 заявлений о перечислении денежных средств. В полном объеме или частично удовлетворены требования 3429 заявителей. В настоящее время НОСТРОЙ выступает ответчиком по 195 судебным искам, связанным с выплатами строителям [11]. 
За время реформы системы саморегулирования общее количество действующих СРО строителей сократилось с 269 до 225, 164 СРО разместили свои компенсационные фонды на специальных счетах в полном размере. На сегодня суммарный компенсационный фонд строительных СРО составляет 80,4 млрд руб.

Внесенные изменения в Градостроительный кодекс РФ и отдельные законодательные акты РФ в части саморегулирования деятельности юридических лиц, осуществляющих негосударственную экспертизу проектной документации и (или) результатов инженерных изысканий направлены на [3]:

- формирование общегосударственной модели саморегулирования в области проведения негосударственной экспертизы проектной документации и результатов инженерных изысканий;

- повышение качества результатов экспертной деятельности, в том числе за счет создания одного вида СРО, а именно: в области экспертизы проектной документации и результатов инженерных изысканий;

- создание единой методологической и нормативно-технической базы обеспечения экспертной деятельности.

В целом данный законопроект получил одобрение профессионального сообщества в части определения правил саморегулирования для юридических лиц, осуществляющих проведение негосударственной экспертизы проектной документации и результатов инженерных изысканий, однако некоторые положения законопроекта требуют доработки.

Подготовленная нормативная база, рассчитанная до 2024 г., должна стать максимально продуктивной, эффективной и не повлечь дополнительного регулирования того, что уже регламентировано, градостроительная политика и жилищно-коммунальное хозяйство, должны быть жизнеспособными, выполнимыми [9].

Еще одной важной проблемой для строительных и проектно-изыскательских организаций является правильный выбор СРО для вступления и получения допуска к соответствующим видам работ. Оценку целесообразно проводить по ряду критериев.

1. Работа СРО на рынке предоставляемых услуг не менее 2 лет. Многие начинающие СРО закрываются после очередной проверки Федеральной службы по экологическому, технологическому и атомному надзору (далее - Ростехнадзор). Дату основания СРО можно установить на сайте Ростехнадзора. Как правило, существующие более 2 лет СРО, имеют опыт в данной сфере, отлаженную систему документооборота и взаимодействия со своими членами. Сотрудничество с такими СРО - простой и быстрый процесс.

2. Количество членов-участников СРО - около 1000 членов юридических лиц и частных предпринимателей. Сегодня зарегистрировано 276 строительных СРО, большая часть которых насчитывает не более 500 членов. Такие СРО не показывают свою численность, поскольку освещение этого факта снижает уровень доверия клиентов. Пользуясь неосведомленностью своих клиентов, представители таких СРО замалчивают численность своих членов или преувеличивают ее в 2-3 раза.

Тем не менее, большое количество членов СРО - это показатель доверия, показатель большого размера компенсационного фонда, который в случае форс-мажорных обстоятельств сможет покрыть возможный ущерб от профессиональной деятельности его членов. Количество членов СРО обязательно должно быть указано на ее сайте в разделе «реестр членов». Отсутствие этой информации - один из признаков того, что СРО принимает новых членов, но не отчитывается об этом в Ростехнадзор. Принятие нового члена в СРО и выдача допуска обязательно должны сопровождаться соответствующей отчетностью в контролирующий орган, в противном случае выданный допуск признается незаконным [8].

3. На сайте СРО обязательно должен быть размещен «открытый» реестр членов по форме, утвержденной Ростехнадзором, в которой отображается информация о членах СРО: наименование организации, ИНН, дата выдачи допуска и его номер, наименование страховой компании, оформившей страховой полис для члена СРО и общее количество членов СРО. Анализ официальных сайтов строительных СРО показывает, что лишь некоторые из них придерживаются утвержденных требований к форме реестра членов.

Открытый реестр, в котором четко видно общее количество членов СРО и приведен их полный перечень - один из важнейших критериев, указывающих на законность деятельности саморегулируемой организации и ее порядочное отношение к своим членам.

4. Оформление допуска должно сопровождаться его регистрацией в Ростехнадзоре, в противном случае, деятельность строительной организации может быть признана незаконным предпринимательством. Особую сложность в реализации процедуры проверки регистрации допуска в Ростехнадзоре создает тот факт, что официальный ответ о действительном занесении допуска СРО в реестр осуществляет только головное подразделение 
Ростехнадзора, находящееся в Москве. Выписка из реестра Ростехнадзора - единственное гарантированное подтверждение, что выданный допуск является законным и дает его обладателю законное право осуществлять указанные в нем виды работ. Большое значение выписка имеет и для заказчика строительных работ - это гарантия застрахованности деятельности строительной организации на полную сумму компенсационного фонда СРО. В большинстве случаев заказчики предпочитают заключать контракты именно с теми строительными организациями, у которых законность допуска СРО подтверждается выпиской из реестра, что многократно увеличивает шансы строительной организации на заключение контрактов или при участии в тендерах и госзаказах.

5. Надежная СРО должна предоставлять только законную рассрочку платежей. Обязательным условием оформления законного допуска является внесение полной суммы взноса в компенсационный фонд СРО (ст. 55.16 Градостроительного Кодекса РФ) и законной признается только такая рассрочка, которая в обязательном порядке подразумевает внесение полной суммы взноса в момент вступления в СРО.

Тем не менее, встречаются случаи, когда СРО предлагает строительной организации оплатить часть взноса в компенсационный фонд, а оставшуюся часть - погашать на протяжении года, иногда и на счет сторонней организации - управляющей компании, которая потом переводит общую накопленную сумму полного размера компенсационного фонда за члена СРО непосредственно на счет СРО. Однако выданный в этом случае допуск признается незаконным и не дает права осуществлять работы с объектами капитального строительства. Одно из самых часто встречающихся предложений на рынке оформления допусков СРО - вступление в рассрочку. Оплата рассрочки напрямую в СРО ведет к получению фиктивного допуска, поскольку не получив от своего члена полной суммы взноса в компенсационный фонд, СРО не отправляет сведения о выданном допуске в Ростехнадзор.

При оформлении законной рассрочки (займа) полную сумму взноса в компенсационный фонд обязательно переводят на счет СРО. Статья 55.16 Градостроительного Кодекса РФ не накладывает ограничений относительно того, кто именно перечислит эту сумму. Благодаря этому становится возможным внесение суммы дочерней компанией. На основании договора займа строительная организация рассчитывается с дочерней компанией на протяжении года. Это делает процесс оформления допуска максимально удобным с финансовой точки зрения, и такой допуск является законным.

Кроме перечисленных критериев мы предлагаем учитывать при оценке надежности СРО процедуру проведения проверок и наличие незначительной судебной практики.

1. Надежность СРО подтверждается также неформальной организацией и достаточной периодичностью проверок членов СРО, что обеспечивает поддержание должного качества ведения строительных работ на объектах членов СРО.

2. Наличие незначительной судебной практики СРО свидетельствует о соблюдении требований законодательства РФ и надзорных органов, что также подтверждает надежность СРО.

Важным вопросом устойчивого развития строительной организации, на наш взгляд, должен стать предупредительный контроль выполнения ими строительных работ на объектах, поскольку государственный надзор на сегодня сведен к контролю над осуществлением членами саморегулируемой организации предпринимательской или профессиональной деятельности путем проведения плановых и внеплановых проверок. Предметом плановой проверки является соблюдение членами саморегулируемой организации требований стандартов и правил саморегулируемой организации, условий членства в саморегулируемой организации. Плановая проверка должна проводиться не чаще одного раза в год. Основанием для проведения внеплановой проверки служит направленная в саморегулируемую организацию жалоба на нарушение строительной организацией-членом саморегулируемой организации требований стандартов и правил саморегулируемой организации. При этом строительная организация обязана предоставить для проведения проверки необходимую информацию по запросу саморегулируемой организации в порядке, определяемом саморегулируемой организацией.

Такой регламент проверки, основанный на изучении документации строительной организации, может недостаточно объективно представить реальную картину на строящемся объекте и не выявить всего комплекса отклонений от проекта, что в целом снизит качество и надежность построенного объекта.

Процедура участия СРО в выявлении и реагировании на нарушения, допущенные строительной организацией, сводится к передаче материалов проверки для рассмотрения дела о применении мер дисциплинарного воздействия. 
Саморегулируемая организация в соответствии с законодательством РФ несет ответственность за неправомерные действия ее работников при проведении контроля над деятельностью строительных организаций - членов СРО. При рассмотрении жалоб о применении в отношении членов СРО мер дисциплинарного воздействия приглашаются обе стороны конфликта.

Уполномоченный представитель СРО по рассмотрению дел о применении мер дисциплинарного воздействия может принимать решения о:

- вынесении предписания, обязывающего устранить выявленные нарушения в установленные сроки;

- вынесении предупреждения;

- наложении штрафа;

- рекомендациях об исключении из членов СРО, подлежащих рассмотрению постоянно действующему коллегиальному органу управления СРО.

Решения принимаются большинством голосов о применении мер дисциплинарного воздействия и вступают в силу с момента их принятия, направляются на бумажном носителе или в форме электронных документов, в том числе копии решения, лицу, направившему жалобу, по которой принято такое решение.

Решения могут быть обжалованы членами СРО в постоянно действующий коллегиальный орган управления СРО в сроки, ею установленные, а также в суде в установленном законодательством РФ порядке.

Денежные средства, полученные саморегулируемой организацией в результате наложения на члена саморегулируемой организации штрафа, подлежат зачислению в компенсационный фонд саморегулируемой организации.

Предупредительный контроль соответствия и качества выполнения строительных работ на объектах обеспечивается в том числе и регулярным надзором со стороны застройщика, который может выполнять функции как заказчика, так и инвестора.

Технадзор в строительстве или строительный надзор - это комплекс экспертно-проверочных мероприятий на соответствие строительства объекта проектной документации, в том числе требованиям энергетической эффективности и требованиям оснащенности объекта капитального строительства приборами учета используемых энергетических ресурсов, который должен проводиться в процессе реализации любого инвестиционно-строительного проекта. Технический надзор в строительстве должен проводиться государственным органом (городским или региональным) - управлением строительного надзора и экспертизы.

В соответствии со Сводом правил СП 48.13330.2011 «Организация строительства» застройщик должен информировать органы, уполномоченные осуществлять государственный строительный надзор, о начале и завершении строительства, возникновении аварийных случаев, взаимодействовать с ними в процессе осуществления строительства, а также при завершении строительно-монтажных работ. При этом в процессе проверки строительного объекта участвуют представитель строительного контроля заказчика, ответственный за производство работ на объекте со стороны подрядчика, ответственный за соответствие объекта требованиям проектной документации и качество проведения работ [4].

Надзор предполагает действие государственных организаций, а функции технадзора заказчика или независимого технадзора теперь отнесены к строительному контролю. «Строительный контроль» - более широкое понятие, чем «надзор». Строительный контроль - это комплекс мероприятий по поддержке надлежащего качества строительства, выполняемых в процессе строительства [10].

Поскольку законодательно не установлено четких задач, полномочий различных надзорных органов, в процедуре осуществления самого контроля и надзора отсутствует четкий регламент. Для органа строительного надзора важна четкая организация работ, квалифицированный, инициативный персонал, налаженная система обмена информацией. Также отсутствуют требования к фирмам, осуществляющим строительный контроль, единственным условием, предъявляемым к фирмам, является то, что они должны быть членами СРО. Некоторые требования прописываются в тендерной документации, по которым выбираются фирмы для осуществления контроля, но это не нормативные документы [10].

Данный процесс контроля предполагает, что предписание может быть выдано как застройщику, так и генеральному подрядчику в зависимости от того, кто несет ответственность за допущенное нарушение.

Проверки при ведении строительства осуществляются должностным лицом в соответствии с утвержденной программой, которая может быть привязана к ответственным этапам производства работ. Количество 
посещений на типовых объектах обычно не превышает шести раз за весь период строительства. Инспектор государственного строительного надзора имеет право:

- беспрепятственно посещать площадку строительства;

- требовать любые технические документы и доступ к ним;

- требовать повторных испытаний в рамках осуществления строительного контроля заказчиком;

- вносить записи по результатам проверок в общий и специальные журналы производства работ;

- составлять протоколы об административных правонарушениях;

- приостанавливать работы до устранения замечаний.

Самым важным этапом является итоговая проверка, по результатам которой либо выдается заключение о соответствии построенного объекта, либо решение об отказе, которое может быть обжаловано застройщиком в судебном порядке.

Специалисты госнадзора проверяют строительный объект на отсутствие дефектов, брака, соответствие проектному перечню применяемых требований, наличие и состояние необходимого пакета документов. В случае выявления каких-либо отклонений или несоответствий от нормативных показателей процесс сдачи объекта может затянуться. В процессе строительства именно своевременный строительный контроль должен играть основную роль.

Саморегулируемая организация, как организация, регулирующая профессиональную деятельность участников строительного рынка, функцией технического надзора не обладает. На крупных и технически сложных объектах существует независимый технический надзор за качеством строительства, который проводится специализированными коммерческими организациями, с допуском СРО, привлекаемыми заказчиком.

Для получения информации на всех этапах проведения строительных работ осуществляется контроль заказчика с помощью привлеченных независимых высококвалифицированных специалистов различного профиля: геодезистов, конструкторов, архитекторов, проектировщиков, сметчиков и других. Специалисты строительного контроля заказчика выполняют полный спектр работ, направленных на выявление соответствия фактического качества и характеристик строящегося объекта требованиям, заложенным в проектно-сметной документации. Перечень выполняемых работ включает весь цикл контроля подготовительных работ, процесс строительства, работы по сдаче объекта в эксплуатацию органам государственного технического надзора. Для повышения эффективности контроля необходимо, на наш взгляд, скоординировать все виды контроля на базе деятельности СРО, к которому относится строительная организация.

Основное различие технического надзора и контроля заключается в том, что осуществление строительного контроля, в отличие от технического надзора, происходит в процессе строительства; технадзор, в отличие от строительного контроля, является функцией государственных органов и проверяет качество работ, в то время как строительный контроль его обеспечивает [7].

К функциям строительного контроля относятся:

- контроль стоимости работ, заложенной в проектно-сметной документации, контроль цен на строительные материалы, привлечения рабочих строительных профессий, уровня оплаты их труда;

- проверка качества выполнения работ и применяемых материалов, согласно строительным нормам и правилам (СНИП), и документов, которые отражают их свойства;

- контроль соответствия заявленного и фактического объемов работ и строительных материалов, контроль остатка количества неиспользованных материалов;

- контроль ведения всей необходимой документации, внесения изменений в документацию, особенно влияющих на стоимость строительства;

- контроль мероприятий, направленных на уменьшение стоимости и продолжительности строительства путем нахождения самых оптимальных проектных решений и эффективной организации труда.

Таким образом, вменение саморегулируемым организациям функций строительного контроля по заданию заказчика в течение всего процесса строительства объекта позволит обеспечить конкурентоспособность строительных организаций на рынке строительных услуг. 


\section{Библиографический список}

1. Федеральный закон «О саморегулируемых организациях» от 01.12.2007 г. № 315-Ф3 (ред. от 03.08.2018 г.) [Электронный ресурс]. - Режим доступа: Справочная правовая система «КонсультантПлюс» http://www.consultant.ru/cons (дата обращения: 27.04.2019).

2. Федеральный закон «О внесении изменений в Градостроительный кодекс Российской Федерации и отдельные законодательные акты Российской Федерации» от 22.07.2008 г. № 148-Ф3 (ред. от 03.07.2016 г.) (с изм. и доп., вступ. в силу c 01.07.2017 г.) [Электронный ресурc]. - Режим доступа: Справочная правовая система «КонсультантПлюс» http://www. consultant.ru/cons (дата обращения: 27.04.2019).

3. Градостроительный кодекс Российской Федерации от 29.12.2004 N 190-Ф3 (ред. от 25.12.2018) [Электронный ресурс]. - Режим доступа: Справочная правовая система «КонсультантПлюс» http://www.consultant.ru/cons (дата обращения: 27.04.2019).

4. СП 48.13330.2011. Свод правил. Организация строительства. Актуализированная редакция СНиП 12-01-2004 (утв. Приказом Минрегиона РФ от 27.12.2010 г. № 781) (ред. от 26.08.2016 г.) [Электронный ресурс]. - Режим доступа: Справочная правовая система «КонсультантПлюс» http://www.consultant.ru/cons (дата обращения: 27.04.2019).

5. Васючкова, О.А.К вопросу о функциях и видах компенсационных фондов саморегулируемых организаций в сфере строительства//Законы России: опыт, анализ, практика. - 2017. - № 8. - С. 54-58.

6. Гринев, В. П. Безопасность и саморегулирование в строительстве: новое в порядке допуска к работам, влияющим на безопасность объектов капитального строительства. Анализ становления и развития института саморегулирования / В. П. Гринев. - М.: ИНФРА-М, 2012. - 264 с.

7. Кузнецова, Н. В. Информационная функция саморегулируемых организаций//Градостроительное право. - 2016. № 1. - С. 42-47.

8. Фархутдинов, Р. Д. Эффективность саморегулирования в строительстве / Р. Д. Фархутдинов. - М.: Юстицинформ, 2016. $-128 \mathrm{c}$.

9. Гальцев, Д. А. Что входит в обязанности строительного контроля [Электронный ресурс]. - Режим доступа: https:/dmstr. ru/articles/chto-vhodit-v-obyazannosti-stroitelnogo-kontrolya/ (дата обращения: 27.04.2019).

10. Стройгазмонтаж [Электронный ресурс]. - Режим доступа: http://www.ooosgm.ru/press/articles/stroitelnyy-kontrol-vmesto-tekhnadzora/ (дата обращения: 27.04.2019).

11. CPO-SSL [Электронный ресурс]. - Режим доступа: https://sro-ssl.ru/dopusk-sro/vybor-nadez-sro/ (дата обращения: 27.04.2019).

\section{References}

1. Federal'nyi zakon «O samoreguliruemykh organizatsiyakh» ot 01.12.2007 g. № 315-FZ (red. ot 03.08.2018 g.) [The federal law «About self-regulatory organizations» dated December 1, 2007 № 315-FZ (with add. on August 3, 2018)]. Available at: Spravochnaya pravpvaya sistema «Konsul'tantPlyus» http://www.consultant.ru/cons (accessed 27.04.2019).

2. Federal'nyi zakon «O vnesenii izmenenii v Gradostroitel'nyi kogeks Rossiiskoi Federasii i otdel'nye zakonodatel'nye akty Rossiiskoi Federatsii» ot 22.07.2008 g. № 148-FZ (red. ot 03.07.2016 g.) (s izm., vstup. v silu s 01.07.2017 g.) [The federal law «About introduction of amendments to the Town-planning code of the Russian Federation and separate acts of the Russian Federation» dated July 22, 2008 № 148-FZ (with add. on July 03, 2016) (with amend. on July 01, 2017)]. Available at: Spravochnaya pravovaya sistema «Konsul'tantPlyus» http://www.consultant.ru/cons (accessed 27.04.2019).

3. Gradostroitel'nyi kodeks Rossiiskoi Federatsii ot 29.12.2004 № 190-FZ (red. ot 25.12.2018) [Urban Development Code of the Russian Federation dated December 29, 2004 № 190-FZ (with add. on December 25, 2018)]. Available at: Spravochnaya pravpvaya sistema «Konsul'tantPlyus» http://www.consultant.ru/cons (accessed 27.04.2019).

4. SP 48.13330.2011. Svod pravil. Organizatsiya stroitel'stva. Aktualizirovannaya redaktsiya SNiP 12-01-2004 (utv. Prikazom Minregiona RF ot 27.12.2010 g. № 781) (red. ot 26.08.2016 g.) [SP 48.13330.2011. Set of rules. Organization of construction. Updated version of SNiP 12-01-2004 (approved by Order of the Ministry of Regional Development of the Russian Federation № 781 dated December 27, 2010) (with add. on August 26, 2016)]. Available at: Spravochnaya pravovaya sistema «Konsul'tantPlyus» http://www.consultant.ru/cons (accessed 27.04.2019).

5. Vasyuchkova O. A. K voprosu o funktsiyakh i vidakh kompensatsionnykh fondov samoreguliruemykh organizatsii v sfere stroitel'stva [To a question of functions and types of indemnification funds of self-regulatory organizations in the sphere of construction]. Zakony Rossii: opyt, analiz, praktika [Laws of Russia: experience, analysis, practice], 2017, I. 8, pp. 54-58. 
6. Grinev V. P. Bezopasnost' i samoregulirovanie v stroitel'stve: novoe v poryadke dopuska k rabotam, vliyayushchim na bezopasnost' ob" ektov kapital'nogo stroitel'stva. Analiz stanovleniya i razvitiya instituta samoregulirovaniya [Safety and self-regulation in construction: new is admission to the works affecting safety of capital construction projects. Analysis of formation and development of institute of self-regulation]. M.: INFRA-M, 2012. 264 p.

7. Kuznetsova N. V. Informatsionnaya funktsiya samoreguliruemykh organizatsii [Information function of self-regulatory organizations]. Gradostroitel'noe pravo [Town-planning law], 2016, I. 1, pp. 42-47.

8. Farkhutdinov R. D. Effektivnost' samoregulirovaniya v stroitel'stve [Efficiency of self-regulation in construction]. Moscow: Ustitsinform, 2016. 128 p.

9. Gal'tsev D. A. Chto vkhodit v obyzannosti stroitel'nogo kontrolya [What belongs to duties of construction control]. Available at: https://dmstr.ru/articles/chto-vhodit-v-obyazannosti-stroitelnogo-kontrolya/ (accessed 27.04.2019).

10. Stroigazmontazh. Available at: http://www.ooosgm.ru/press/articles/stroitelnyy-kontrol-vmesto-tekhnadzora/ (accessed 27.04.2019).

11. SRO-SSL. Available at: https://sro-ssl.ru/dopusk-sro/vybor-nadez-sro/ (accessed 27.04.2019). 